\title{
Musculoskeletal ultrasound (MSK-US) in pediatric rheumatology: European preliminary results of the survey of the Pediatric Ultrasound Group of the Omeract Ultrasound Task Force
}

\author{
Silvia Magni-Manzoni ${ }^{1}$, Johannes Roth ${ }^{2}$, Paz Collado ${ }^{3}$, Esperanza Naredo ${ }^{3}$, Maria Antonietta D'Agostino ${ }^{4}$, \\ Pietro Merli ${ }^{5}$, Valentina Muratore ${ }^{5^{*}}$, Sandrine Jousse-Joulin ${ }^{6}$
}

From 18th Pediatric Rheumatology European Society (PReS) Congress

Bruges, Belgium. 14-18 September 2011

\section{Background}

Despite the growing interest and use of MSK-US in children, its current use in paediatric rheumatology is not known.

\section{Objectives}

To identify the current use of MSK-US and the areas most suitable for its development and standardisation in paediatric rheumatology.

\section{Methods}

A questionnaire of 10 single or composite questions, including professional data, current use in daily practice, current clinical relevance of the main features of MSKUS, and areas for prospective development, has been sent to the members of PRINTO/PRES.

\section{Results}

92/389 (24\%) answers have been collected from 37 countries. The responders are mainly pediatric rheumatologists $(80 \%)$, have a long-lasting clinical experience in paediatric rheumatology ( $74 \%>10$ years), and are more clinicians $(>70 \%)$ than researchers $(24 \%)$.

MSK-US is used in clinical practice by $>90 \%$ : personally by $40 \%, 49 \%$ by the radiologist, $16 \%$ by the adult rheumatologist. The most relevant features of MSK-US are the high patient's acceptability $(76 \%)$, the immediate improving of diagnosis of joint and soft tissue disease (73\%), the assessment of synovitis and tendons/ tendons'sheaths (73\% and 70\%), and the support to imaging guided joint injections (67\%). The anatomical sites best suited for MSK-US are hips (87\%), ankles (78\%), wrists (65\%), knees (64\%), and mid-foot (63\%). MSK-US is considered important for diagnosis, therapy monitoring, and research (70\%).

\section{Conclusions}

We identified the current use of MSK-US in paediatric rheumatology among the European network of PRINTO/PRES. The results outline the major reasons and areas of interest, useful for future steps towards a wider international standardized development of MSKUS in paediatric rheumatology.

\section{Author details \\ ${ }^{1}$ Fondazione IRCCS Policlinico S.Matteo, Pavia, Italy. ${ }^{2}$ Children's Hospital of Eastern Ontario, Ottawa, Canada. ${ }^{3}$ Department of Rheumatology, Hospital Severo Ochoa, Madrid, Spain. ${ }^{4}$ DpRheumatology,Université deVersailles St- Quentin-en Yvelines, Ambroise Paré Hospital, Boulogne-Billancourt, France. ${ }^{5}$ DpPediatrics, Fondazione IRCCS Policlinico S.Matteo, Pavia, Italy. \\ ${ }^{6}$ Rheumatology Unit and Immunology Laboratory, Université de Bretagne} Occidentale, Brest, France.

Published: 14 September 2011

doi:10.1186/1546-0096-9-S1-P47

Cite this article as: Magni-Manzoni et al:: Musculoskeletal ultrasound (MSK-US) in pediatric rheumatology: European preliminary results of the survey of the Pediatric Ultrasound Group of the Omeract Ultrasound Task Force. Pediatric Rheumatology 2011 9(Suppl 1):P47.

${ }^{5}$ DpPediatrics, Fondazione IRCCS Policlinico S.Matteo, Pavia, Italy

Full list of author information is available at the end of the article

(c) 2011 Magni-Manzoni et al; licensee BioMed Central Ltd. This is an open access article distributed under the terms of the Creative 